\title{
Effect of Irrigation Dose Based on Vegetation Indices Calculation Using Multispectral Sensor
}

\author{
C. D. Papanikolaou ${ }^{1} \&$ M. A. Sakellariou-Makrantonaki ${ }^{1}$ \\ ${ }^{1}$ Department of Agriculture, Crop Science and Rural Environment, Laboratory of Agricultural Hydraulics, \\ University of Thessaly, Volos, Greece
}

Correspondence: C. D. Papanikolaou, Department of Agriculture, Crop Science and Rural Environment, Fytokou Street, 38446, Volos, Greece. E-mail: hpapan@uth.gr

Received: May 23, 2020

Accepted: August 5, $2020 \quad$ Online Published: October 15, 2020

doi:10.5539/jas.v12n11p107

URL: https://doi.org/10.5539/jas.v12n11p107

The research is financed by the «Stavros Niarchos Foundation» in the frame of the invitation "SCHOLARISHIP GRANTING FOR POST-DOCTORATE RESEARCH" of the University of Thessaly, which is implemented by the University of Thessaly.

\begin{abstract}
The agricultural sector is vital for the Greek economy, the Greek producers and consumers. The new era in agriculture leads scientists to find new more effective ways to estimate plant growth and biomass production and to increase water use efficiency. Given the above, a research project was organized at the Laboratory of Agricultural Hydraulics, University of Thessaly. For the first time in the climatic conditions of Central Greece, the project aims to assess another method to estimate the growth and biomass production of corn, based on multispectral photos and vegetation indices using a low cost multispectral camera and drone. Three surface drip irrigation treatments in three replications were organized and a randomized complete block design was used. The crop water needs were calculated according to the daily evapotranspiration using the Penman-Monteith procedure as it was presented by the Food Agricultural Organisation. The amount of water in each treatment was equal to A) $100 \%$ of the daily evapotranspiration (ETo), B) $75 \%$ of the ETo, and C) $50 \%$ of the ETo. Vegetation indices were calculated based on multispectral photos taken from a drone and the Simple and Multiple Regression analysis were used to estimate the maize growth and biomass production in Greek conditions. Different equations were formed to estimate the maize growth and biomass production and vegetation indices were used as independent variables. The results showed that vegetation indices can be used in the agriculture process to estimate maize growth and biomass production. In this paper the results of two consecutive years, 2018 and 2019 are presented.
\end{abstract}

Keywords: remote sensing, vegetation indices, multispectral photos, drone, water use efficiency

\section{Introduction}

Worldwide agriculture has entered a new era dominated by the application of new technologies and methods in agricultural production. On the contrary, in Greece, the agricultural sector still follows conventional practices and sometimes seems to be against the introduction of the new technologies in agricultural production. Furthermore, the production cost is high as a result of the high prices of crude oil which affects the cultivation cost and the irrigation cost as well. The irrigation cost is affected by the methods of irrigation scheduling that are used too. The agricultural sector is one of the pillars of the Greek economy alongside tourism and is a resource of income for thousands of Greek families. Consequently, the above limitations are crucial for the development of the Greek agricultural production which makes it necessary for the scientific community to focus on finding solutions.

New technologies have not entered the Greek agricultural production as dynamically as it was expected. Different factors have not allowed Greek farmers to extensively implement new technologies into the agricultural process and production. The most significant of these factors is the economic crisis that the country has experienced in the last decade. Its impact is still visible today. The decrease in the country's gross domestic 
product (GDP) has also resulted in a reduction in the funds available for investment in new technologies and practices in agriculture.

At the same time, the agricultural sector in Greece faces specific problems that require solutions. One of them is the high cost of irrigation water as a result of the limited quantities available for agricultural use. It is well known that climate change has also affected Greece. As a result, an uneven distribution in rainfall water has been observed both geographically and in terms of time and duration. The consequence of this is that certain areas receive high amounts of rainwater without having the necessary infrastructure to store and to utilize these quantities of water while rainwater occurs at a time when crops have no water requirements. It is therefore necessary to develop techniques for the optimal management of available water to meet the needs of agriculture using new techniques.

Researchers in the past have suggested practices for optimal irrigation water management. Drip irrigation was initially suggested, as it has minimal losses of water while it gives a high yield. Also, it is more feasible to use automation with drip irrigation systems in comparison with other methods such as sprinkler irrigation. Later, modern irrigation scheduling methods were used through the use of reference evapotranspiration (ETo) calculation methods such as the methodology presented by Allen et al. (1998), replacing other methods such as the evaporation pan class A and others. Soil moisture sensors were hardly applied to open field crops as opposed to greenhouse crops. Efforts have recently been made to apply remote sensing techniques and satellite imagery to assess soil moisture status and to implement an irrigation program. Each of the above methods has limitations. For example, measurements of the reference evapotranspiration using simple methods (Penman, Hargeaves, evaporation pan class A) causes over or underestimations of the ETo, whereas the FAO Penman-Monteith method requires detailed climatic data that is difficult to collect. Soil moisture sensors have high purchase and installation costs, while photos taken from satellites are expensive too and have altitude inaccuracies as well as repeatability problems (Jiang et al., 2015; Radhadevi et al., 2016).

Another recurrent problem is the high cost of energy for agricultural use. In Greece, a significant part of energy needs is covered by oil. Oil, among other uses, is used in all agricultural machinery that is used in farming and in some cases in pumping irrigation water. In the last seven years, this problem has not been so serious due to the low price of crude oil. However, the price of crude oil is not steady due for several reasons including the health crisis (http1), thus occasionally the use of oil to pump irrigation water is not affordable. On the other hand, it is more expensive to use electricity in some cases, due to the high cost of the solid fossil fuels like lignite which is the main raw material in power production, whereas the whole procedure increases the greenhouse gas emissions (Tursi, 2019). The solution, in this case, is the use of renewable energy sources, such as biomass. Biomass can be used either as the raw material for solid fuels (pellets) or liquid fuel production (bioethanol) (Karatassiou et al., 2016a, 2016b; Papoutsidakis et al., 2018).

All of these concerns are being addressed and a new era for agricultural production has begun by using unmanned aerial vehicles (drones) in conjunction with various multispectral sensors. The most up-to-date practice is to use multispectral cameras and drones to calculate specific vegetation indices related to the plant's physiological condition and to provide information on the plant's health. The gradual progress of the research has led to finding of several such indices each associated with estimating different parameters such as Leaf Area Index (Potgieter et al., 2017), Soil Moisture (Belvert et al., 2012), biomass production (Gitelson, 2004). The best known of these indices is the NDVI (Normalized Difference Vegetation Index). International studies have shown that this vegetation index can be used to predict various parameters related to plant growth (Toureiro et al., 2017) For example, it can be used to predict possible plant stress due to pathogens up to two weeks before symptoms become apparent (Shawn, 2017) or to assess the potential lack of moisture in the field (Sruthi and Aslam, 2014) and to estimate the crop yield (Mulla, 2013), including biomass production (Latifia et al., 2015) and plant height (Payero et al., 2004).

However, there are limited references to the use of vegetation indices based on low cost multispectral camera and drone combination in agricultural production. Especially, there are no studies that correlate specific vegetation indices with irrigation management, growth and biomass estimations in the climatic conditions of Central Greece.

In the present research, a drone and a multispectral camera were used to take photographs of a corn crop. Corn is a plant that is ideally adapted to the climatic conditions of Greece. It is an important crop for the Greek economy, mainly for its high nutritional value for both humans and animals. Also, it is one of the cultivated plant species that give a significant production of both biomass and bioethanol (Ambrosio et al., 2017). Finally, it is a plant that is affected by different irrigation doses (Toureiro et al., 2017). 
This research started in 2018 and its total duration is three years. The objective is dual. Initial main aim is to study the feasibility of using a drone and a multi-spectral camera to calculate vegetation indices in corn in the Greek climatic conditions. Additionally, it aims to study whether it is possible to use these vegetation indices to estimate the corn height and the dry biomass production under different irrigation doses. The main hypothesis was that if specific vegetation indices can be used to estimate the corn height and biomass production in the climatic conditions of Central Greece. The secondary hypothesis was that if the irrigation dose might affect the kind of vegetation index that is going to be used as independent variable in plant height and biomass production estimation.

Based on the previous paragraphs this study has theoretical and practical implications as well. As previously mentioned it is the first time that such a low cost technique has been applied in the Greek climatic conditions. The collected know-how is going to be used as the basis for other research projects in the future. Furthermore, the knowledge is going to be used in training programs for farmers as well as in the under graduate and post graduate programs. Practically, the know-how is going to be used in every day agricultural practice for an optimal management of the natural resources such as irrigation water so as to save it and to economise and improve water use efficiency.

\section{Materials and Methods}

\subsection{Cultivation and Irrigation Techniques}

A research project was designed and implemented at the Experimental Farm of the Department of Agriculture, Crop Production and Rural Environment, in the Velestino area, Magnesia, Central Greece in 2018. In this paper the results from the first two years 2018 and 2019 are presented. The local altitude of the farm is about 70 meters above sea level. The complete randomized block experimental design was used (Mongomery and Runger, 2003) with three irrigation treatments in three replications. The treatments were: a) surface drip irrigation (I-100) with irrigation dose equal to $100 \%$ of daily evapotranspiration (ETd), b) surface drip irrigation (I-75) with irrigation dose equal to $75 \%$ of the ETd and c) surface drip irrigation (I-50) with irrigation dose equal to $50 \%$ of the ETd. The data was analysed with the Statistical Package Minitab ver. 16 for Windows. The one-way analysis of variance (ANOVA) and the Simple and Multiple Linear Regression analysis tools were applied and the significance level was $\mathrm{P}<0.05$. The regression analysis was used to calculate equations to predict specific plant characteristics. Several vegetation indices were the independent variables while the dependent variables were the plant height of the crop and biomass production. This procedure was used to study the main hypothesis (if specific vegetation indices can be used to estimate the corn height and biomass production in the climatic conditions of Central Greece). Different vegetation indices were calculated for each of the three treatments so as to study the secondary hypothesis (if the irrigation dose might affect the kind of vegetation index that is going to be used as independent variable in plant height and biomass production estimation).

The corn was sown on 04/17/2018 and 04/22/2019 with a four-row seeder. Each of the four rows consisted of 96 plants so the distance between the plants was $13 \mathrm{~cm}$ while the distance between the rows was $80 \mathrm{~cm}$. The total area of each plot was $30 \mathrm{~m}^{2}$. So, the total number of plants per ha was 9,600. The harvested took place in the second 10-days of September (728 Growing Degree Days). The treatments were free of nitrogen fertilization and the weeds controlled through two chemical applications. The first weed control was applied before the plant emergence and the second one after the emergence.

The crop evapotranspiration (ETc) method was used in irrigation dose calculations. The FAO Penman-Monteith equation was used to calculate the reference evapotranspiration (ETo) as well as the simple crop coefficient (Allen et al., 1998). The daily meteorological data by an agrometeorological station as well as the daily ETo were recorded. The station is located $50 \mathrm{~m}$ from the treatments.

The irrigation doses were applied through a drip irrigation system. First and second class delivery laterals of polyvinyl chloride (PVC) were used. The distance between the drip laterals was $1.60 \mathrm{~m}$. The distance between the emitters was $0.50 \mathrm{~m}$ with an average flow rate of $4 \mathrm{l} / \mathrm{h}$. The drip irrigation program started on $05 / 16 / 2018$ and $05 / 31 / 2019$. During the first cultivation period in 2018, two sprinkler irrigations were applied to achieve the optimal crop emergence while the next year three sprinkler irrigations were applied. Flowmeters were placed in each plot and the exact amount of irrigation water was recorded after every irrigation. The irrigation dose was applied every six days. The irrigation dose was applied every six days two days earlier than the maximum irrigation interval which calculated according to the field properties (Papanikolaou \& Sakellariou-Makrantonaki, 2019).

Weekly measurements of plant height and biomass were taken. The measurements of height were taken from the two middle rows of each plot. Every plant from an area of $2 \mathrm{~m}^{2}$ was measured. Every week a plant from each 
plot was chosen randomly and its fresh biomass was measured. Afterwards the sample plants were dried in an oven for two days (until constant weight) at $105^{\circ} \mathrm{C}$.

\subsection{Meteorological Data}

The climatic type of the area is characterized as a typical Mediterranean climate. The summers are hot while the winders are cool and humid. An agri-meteorological automated station was used to record meteorological data daily. This data was compared with historical data about the area covering the last 25 -years (average values). The station was situated $20 \mathrm{~m}$ far from the first treatment and about $70 \mathrm{~m}$ far from the last one. The mean daily air temperature and the total rainfall water (10-day average values) in the farm area, during the 2018 and 2019 cultivating periods are shown in Figures $1 \mathrm{a}$ and $1 \mathrm{~b}$, schematically and are compared to the corresponding average values of the last 25 years. This figure shows that in both years (2018-2019) the mean air temperature did not diverge much from the values of an average year. However, during the period from May to August 2018, the mean temperature was lower than the average values of the last 25 years. The difference was $2{ }^{\circ} \mathrm{C}$ to $3{ }^{\circ} \mathrm{C}$ while the maximum value, $6{ }^{\circ} \mathrm{C}$, was recorded the last ten-days of June. On the other hand, during the 2019 period, the air temperature was much closer to the average year, with an exception from 10 to 20 of July when the temperature fell as a result of rainfall water.

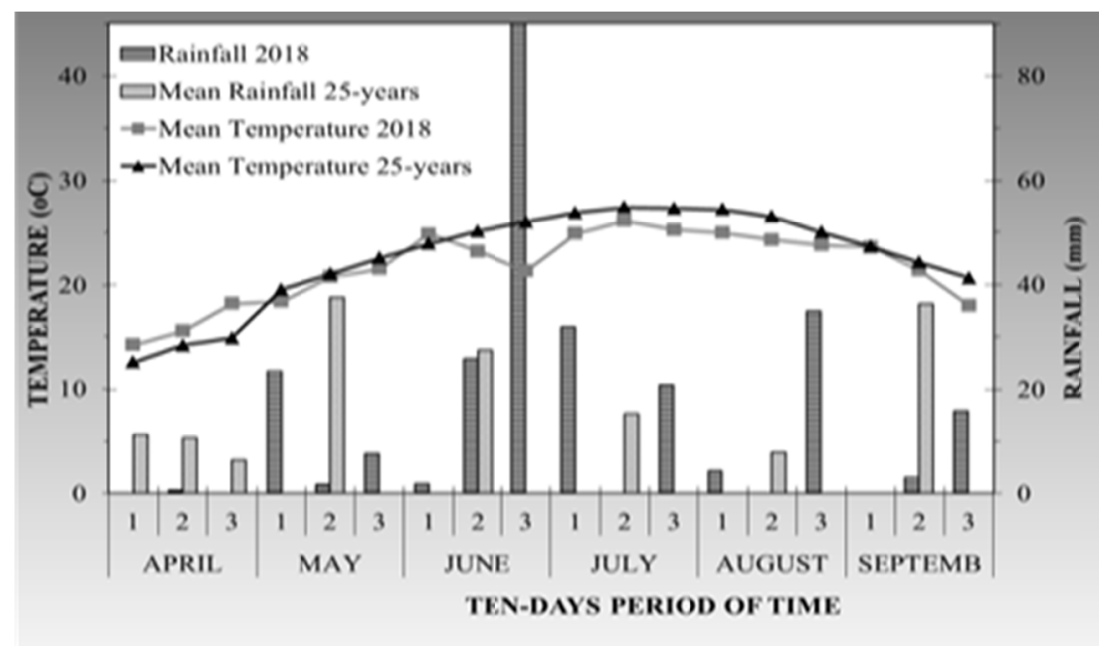

(a)

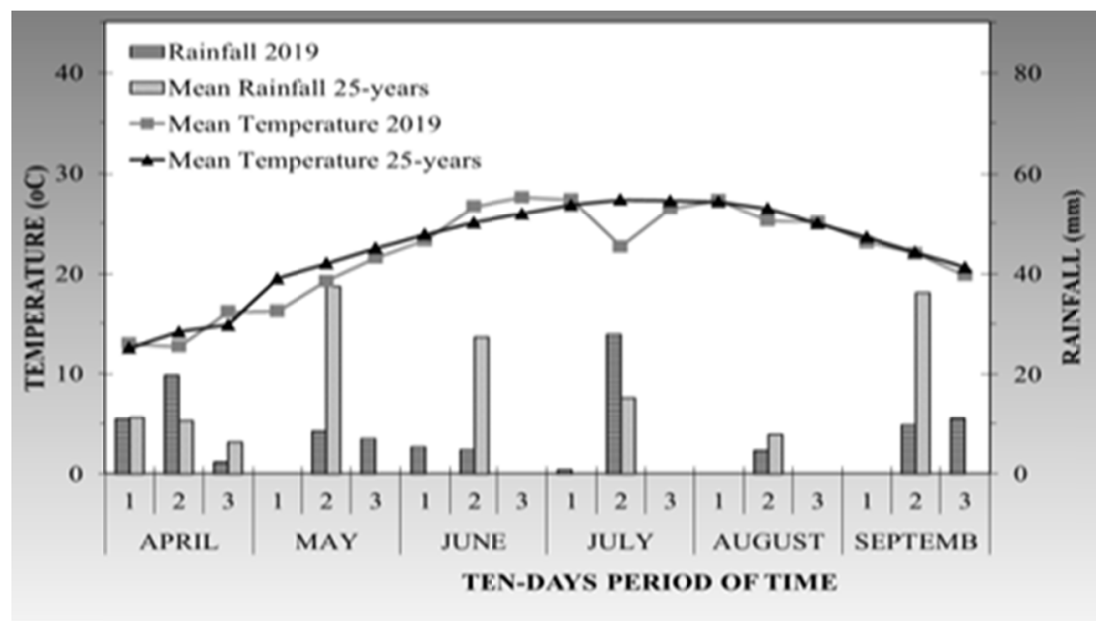

(b)

Figure 1. Mean Temperature and Rainfall during 2018 (a) and 2019 (b) compared to mean values of the last 25 years

During the cultivating period of 2018 , the rainfall water was high. The total amount of the actual rainfall water 
between the sowing date and the end of August was $242.0 \mathrm{~mm}$. About half of this rainfall water $(118.0 \mathrm{~mm})$ fell during the period between 10 of June to 10 of July. During this specific period, the corn growth was rapid and its water needs were high and were covered fully by the rainfall water, only. According to the recorded climatic data of the area, about five more irrigations would have normally been applied. The next year (2019) the total actual rainfall water between the sowing date and the end of August was $41.0 \mathrm{~mm}$, only. During the irrigation period, the rainfall water was only $23 \mathrm{~mm}$ and the crop water needs were mainly covered by irrigations.

\subsection{Vegetation indices Theory}

In the present study, the vegetation indices that were used were the NDVI, the WDRVI, and the RVI. All three vegetation indices were used to estimate the plant height as well as the biomass production. Those indices referred to one plot basis and an average value of each index per treatment was calculated. The NDVI is a commonly known vegetation index and is used to estimate the leaf structure, the leaf area index (LAI), and the photosynthetic canopy (Shawn, 2017; Xu \& Su, 2017). The NDVI (Normalized Difference Vegetation Index) is calculated with the following equation (Xu \& Su, 2017):

Where,

$$
N D V I=\frac{N I R-R E D}{N I R+R E D}
$$

NIR: is the near-infrared channel of the multi-spectral camera centered at $660 \mathrm{~nm}$ with an interval -10 to $+10 \mathrm{~nm}$; RED: is the red channel of the multi-spectral camera centered at $850 \mathrm{~nm}$ with an interval -20 to $+20 \mathrm{~nm}$.

The WDRVI (Wide Dynamic Range Vegetation Index) can be used to estimate biomass when the LAI is higher than 2 while the NDVI is used when the LAI is lower than 1 (Gitelson, 2004). This index is calculated with the following equation (Gitelson, 2004):

$$
W D R V I=\frac{a N I R-R E D}{a N I R+R E D}
$$

Where,

a: is a coefficient value of 0.20 .

The RVI (Ratio Vegetation Index) is used to estimate the leaf area index (LAI), the dry biomass of the plant leaves, and the leaf chlorophyll content (Sun et al., 2011). This index is calculatedwith the following equation:

$$
R V I=\frac{N I R}{R E D}
$$

The GVI (Green Vegetation Index) is used to estimate the biomass (Xue et al., 2004). This index is calculated with the following equation:

$$
G V I=\frac{N I R}{G R E E N}
$$

A multi-spectral camera was used to take photos of the experimental field during the cultivation period. These photos were used to calculate the above vegetation indices. This multi-spectral camera uses three different channels, the red (RED $660 \mathrm{~nm}$ ), the green (Green, $550 \mathrm{~nm}$ ), and the near-infrared (NIR, $850 \mathrm{~nm}$ ). It could be remotely controlled via WiFi with a simple smartphone where appropriate software had been installed. Both the longitudinal and the lateral image overlap were set above $70 \%$. The drone was almost staytionary above the centre of each plot. The focal length.of the camera is $3.37 \mathrm{~mm}$ and the camera angle $87^{\circ}$. The exposure value of the camera is 15.5 . The spatial resolution of the camera is $5.5 \mathrm{~cm} / \mathrm{px}$ at $120 \mathrm{~m}$ altitude. The empirical line method of radiometric calibration was used according to the manufacturer's suggestions. A group of four different ground targets with known and stable reflectance was used. An image of the ground targets was taken before the drone flight and it was used as the reference image in the Camera Control Application software that supports the multispectral camera. Through that software the images were calibrated as for reflectance and atmospheric values even in the case of low flying height of the drone ( $4 \mathrm{~m}$ above the ground). In that way the group of images of each plot for each date were comparable. The general procedure consisted of 4 steps. In the first one the multispectral images were taken. Afterwards the images were processed with the Camera Control Application and the ImageJ software. In the third step the QGIS software was used and the vegetation indices were calculated and the last step was the visualisation. The photos were geo-referenced through a GPS that was connected to the camera. Additionally, the QGIS ver. 2.18, was used. The QGIS was used to calculate the vegetation indices as well as for the geometric correction of the images. For the geometric correction of the images, the ground control point's procedure was used. One ground point in the middle of each plot was marked and its exact coordinates 
were taken using the GPS of a smartphone in decimal degrees form.

Both the multispectral camera and the GPS were attached to an unmanned aerial vehicle (Drone). The full equipment (drone and camera) was used to take photos from a specific height of about $4.0 \mathrm{~m}$ above the ground in each plot in the afternoon (between 12:30 and 14:30 at the sun's zenith) (Foster et al., 2017) when the sun's altitude is about 64 to 72 degrees and the azimuth is 133 to $216^{\circ}$ (SunEarthTools, 2020).

\section{Results}

\subsection{Plant Height, Biomass Production and Water Use Efficiency}

One of the parameters of plant growth is height development. Due to the different irrigation doses that were applied to each treatment the plant height was different, as shown in Figure 2.

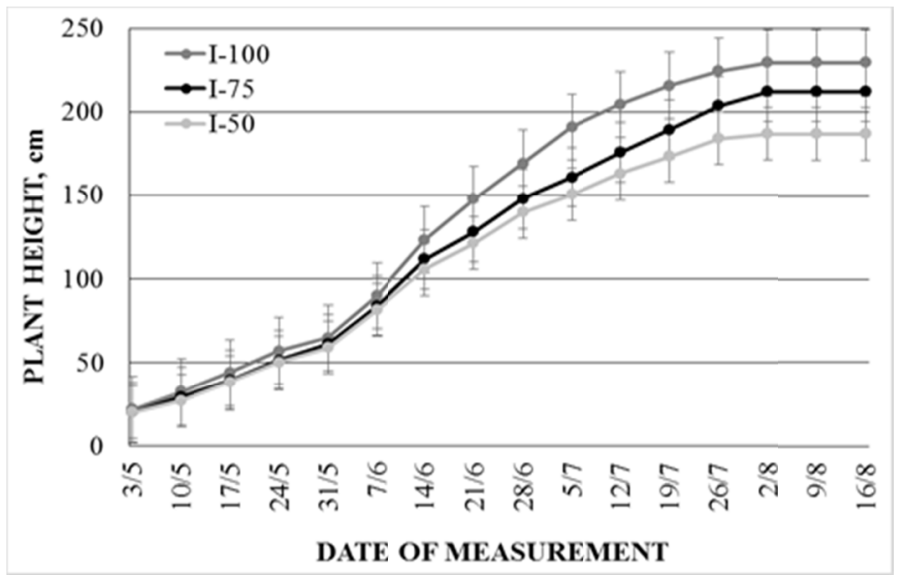

Figure 2. Variation of the average max plant height in the three treatments during the years 2018-2019.

The maximum plant height in the three treatments had a statistically significant difference at the significance level $\mathrm{P}<0.05$.

Another parameter that describes the plant growth is the production of dry biomass. Biomass as well as plant height are affected by the irrigation dose. There were statistically significant differences too.

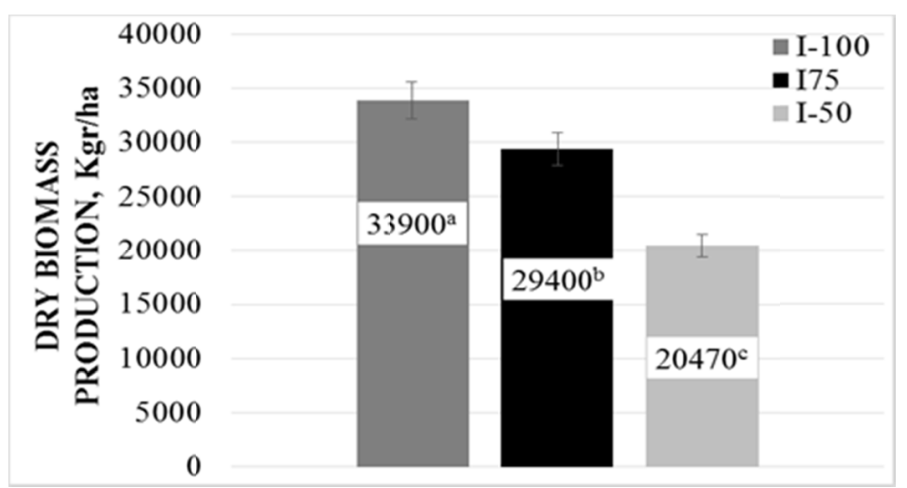

Figure 3. The average maximum dry biomass production of the years 2018-2019

The water use efficiency (WUE) is an important parameter that measures whether an irrigation program is successful or not. Howell et al. (1990) defined the water use efficiency as the quotient between the total yield (dry biomass production in this study) and the total amount of irrigation water. The total amount of irrigation water is the sum of the amount applied through sprinkler irrigation during the period after sowing and the amount that applied through drip irrigation. Table 1 gives the average maximum values of dry biomass, the average amount of irrigation water, and the average WUE for the years 2018-2019. According to these values, the WUE in I-50 treatment is significantly higher than in the treatment I-100 while it seems to have no 
significant difference from the I-75 treatment.

Table 1. Water use efficiency (mean values of the years 2018-2019)

\begin{tabular}{llll}
\hline Treatment & $\begin{array}{l}\text { Mean Dry Biomass Production (kg/ha) } \\
\text { (a) }\end{array}$ & $\begin{array}{l}\text { Mean amount of Irrigation Water }(\mathbf{m m}) \\
\text { (b) }\end{array}$ & $\begin{array}{l}\text { WUE }\left(\mathbf{k g} / \mathbf{m m} \mathbf{H}_{2} \mathbf{O}\right) \\
(\mathbf{c})=(\mathbf{a}) /(\mathbf{b})\end{array}$ \\
\hline I-100 & $33900^{\mathrm{a}}$ & 4470 & $7,58^{\mathrm{c}}$ \\
$\mathrm{I}-75$ & $29400^{\mathrm{b}}$ & 2900 & $10,16^{\mathrm{a}}$ \\
$\mathrm{I}-50$ & $20470^{\mathrm{c}}$ & 1920 & $10,66^{\mathrm{a}}$ \\
\hline
\end{tabular}

\subsection{Vegetation Indices Measures}

The values for each of the four vegetation indices are shown in Figures 4 to 7 . The statistical analysis of the average maximum values showed that there was a statistically significant difference between the treatments $(\mathrm{P}<$ $0.05)$. The treatment I-100 gave the highest NDVI (0.72a) while the NDVI in the I-75 treatment was $0.69 \mathrm{~b}$ and in the I-50 one $0.64 \mathrm{c}$.

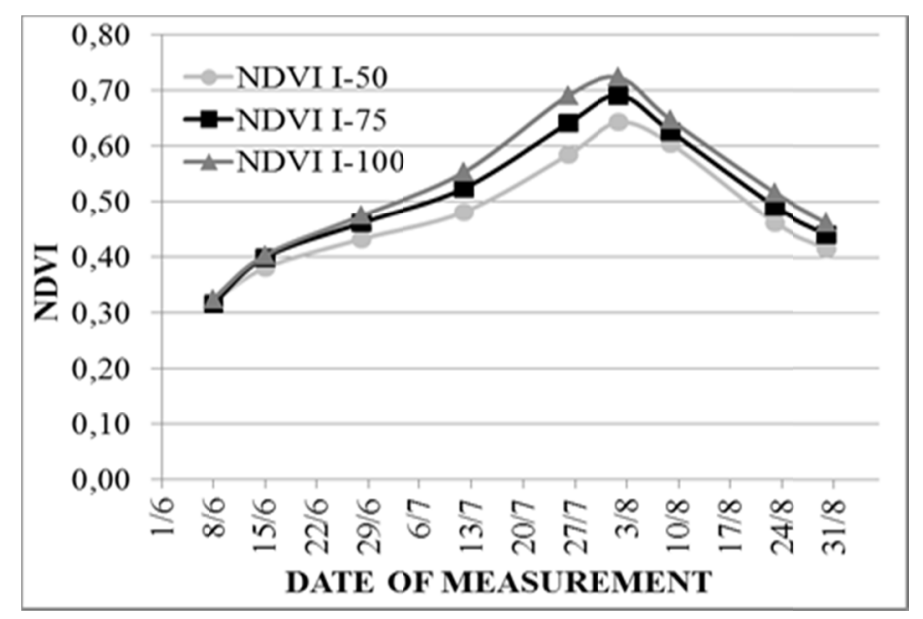

Figure 4. Mean NDVI values of the two years (2018-2019)

The RVI index increased in the same way as NDVI as Figure 5 shows. The values of RVI were significantly different between the treatments. The RVI values were significantly different in the treatments I-100 (8.62a) and I-50 (6.27b) while the treatment I-75 did not differed significantly neither from the I-100 treatment or the I-50 one.

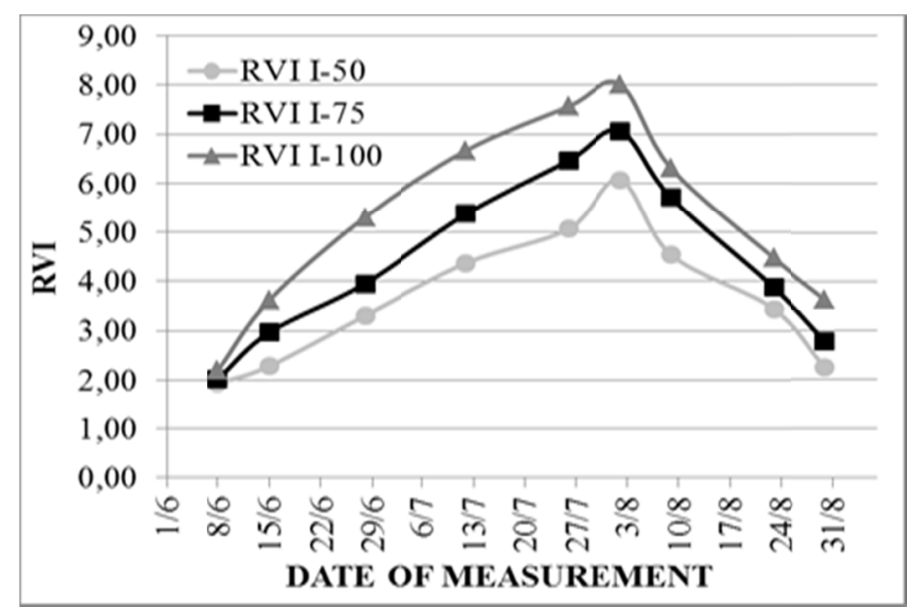

Figure 5. Mean RVI values of the two years (2018-2019) 
The third vegetation index (WDRVI) increases and decreases like the other two indices (NDVI and RVI), as Figure 6 shows. The average maximum WDRVI values were significantly different between the treatments I-100 $(0.23 a)$ and I-50 $(-0.12 b)$, while the I-75 differed significantly from the I-50 treatment but not from the I-100 one.

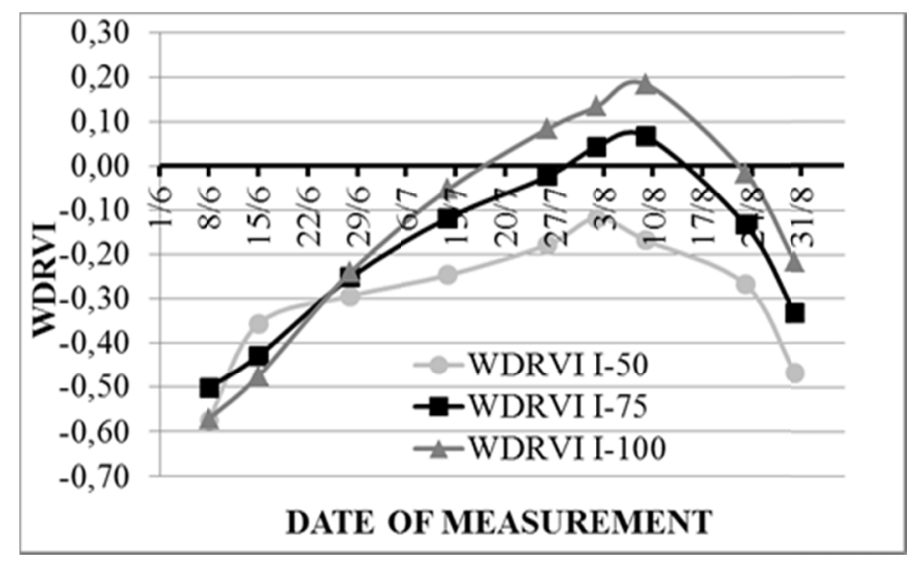

Figure 6. Mean WDRVI values of the two years (2018-2019)

The forth vegetation index, the GVI increased like the other three indices (Figure 7).

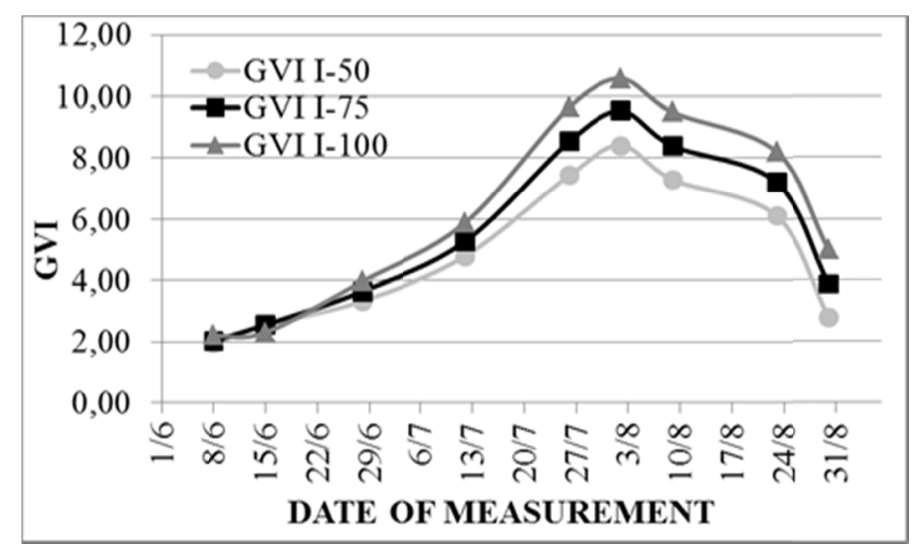

Figure 7. Mean GVI values of the two years (2018-2019)

The average maximum GVI values were significantly different between the treatments. The treatment I-100 gave the highest value (10.58a) and the I-50 one the lowest (8.41c) while the GVI in the I-75 treatment was 9.53 b.

\subsection{Estimation of Plant Height and Biomass Production Using Vegetation Indices}

One of the objectives of this study is to examine whether vegetation indices could be used to estimate plant height and dry biomass production. To estimate the average plant height the NDVI and RVI indices were used. The dependent variable was the average value of the plant height per week of the growing season and the independent variables were the NDVI and RVI indices as they varied every week of the corn growing season. The Simple and the Multiple Regression methods were used to analyse the data and to form the equations.

A) The average plant height of the treatment I-100 is described by the following equation:

$$
H_{100}=285+249 \times W D R V_{100}-11.7 \times R V_{100}
$$

The above equation describes the plant height in high accuracy as the correlation coefficient was found to be $\mathrm{R}^{2}$ $=84.7 \%$.

B) The average plant height of the treatment I-75 is described by Equation 6 : 


$$
H_{75}=-116+1045 \times N D V I_{75}-54.9 \times R V_{75}
$$

The above equation describes the plant height in acceptable accuracy as the correlation coefficient was found to be $\mathrm{R}^{2}=77.1 \%$.

C) The average plant height of the treatment I-50 is described by Equation 7 :

$$
H_{50}=-23.3+553 \times N D V I_{50}-23.2 \times R V_{50}
$$

The above equation describes the plant height in medium accuracy as the correlation coefficient was found to be $\mathrm{R}^{2}=62.3 \%$.

Following the same approach, another three equations were formed to estimate the average dry biomass for each treatment.

D) The average dry biomass of the treatment I-100 is described by the following equation:

$$
D B_{100}=545-54.7 \times R V_{100}+588 \times W D R V I_{100}
$$

The above equation describes the plant height in acceptable accuracy as the correlation coefficient was found to be $\mathrm{R}^{2}=79.8 \%$.

E) The average dry biomass of the treatment I-75 is described by the Equation 9:

$$
D B_{75}=-371+2318 \times N D V I_{75}-148 \times R V I_{75}
$$

The above equation describes the plant height in medium accuracy as the correlation coefficient was found to be $\mathrm{R}^{2}=70.5 \%$.

F) The average dry biomass of the treatment I-50 is described by the Equation 10 :

$$
D B_{50}=-120+867 \times N D V_{50}-50.7 \times R V_{50}
$$

The above equation describes the plant height in medium accuracy as the correlation coefficient was found to be $\mathrm{R}^{2}=61.1 \%$.

Where,

Hi: denotes the average plant height of each treatment for the two years 2018-2019; NDVIi: denotes the average NDVI of each treatment for the same two years; RVIi: denotes the average RVI of each treatment for the same two years; WDRVIi: denotes the average WDRVI of each treatment for the same two years.

The visualization of the real values of plant height and biomass production is shown in Figures $8 \mathrm{a}$ and $8 \mathrm{~b}$ respectively. 


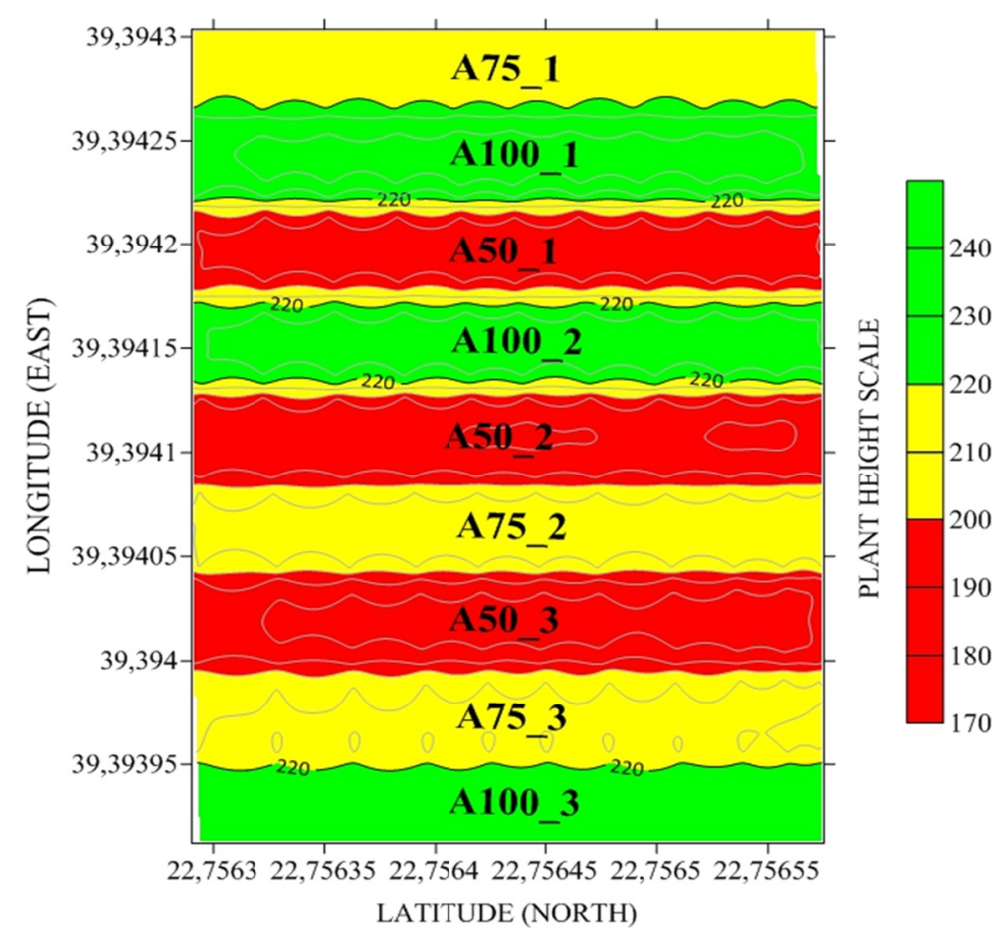

(a)

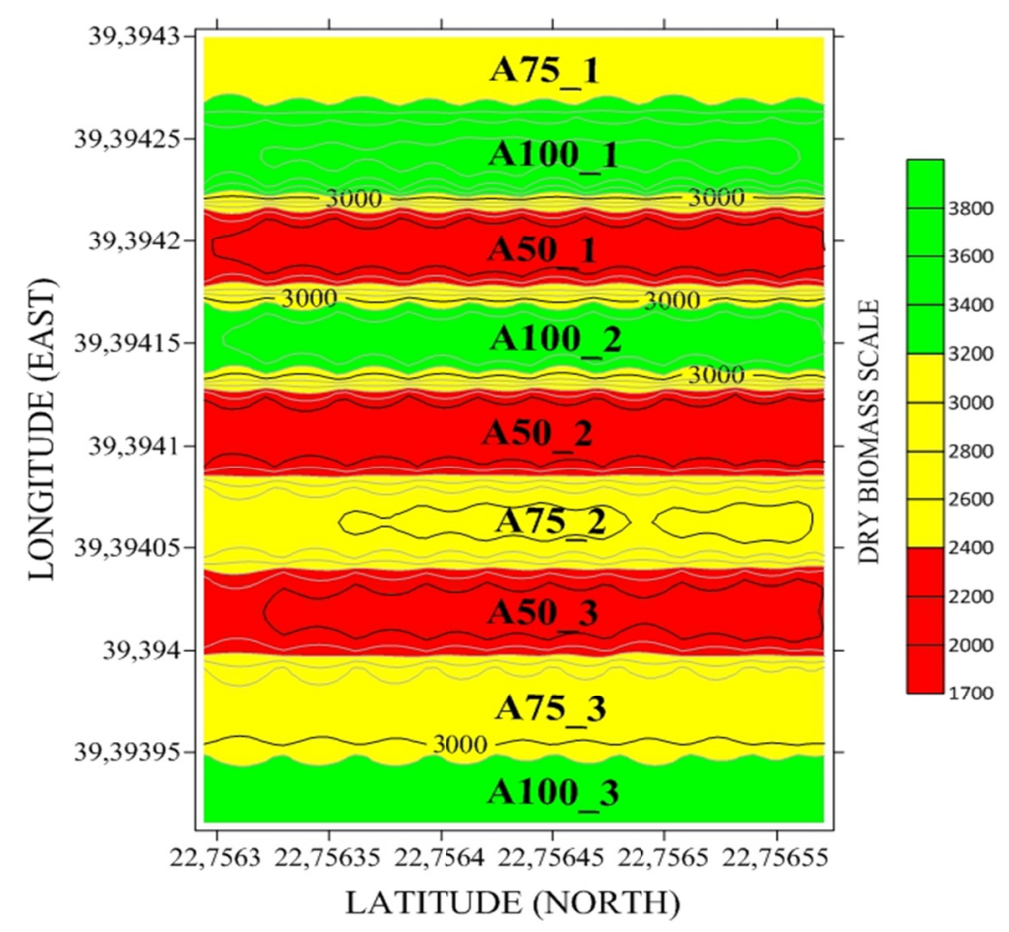

(b)

Figure 8. Visualization of the real values of plant height (a) and dry biomass production (b) 

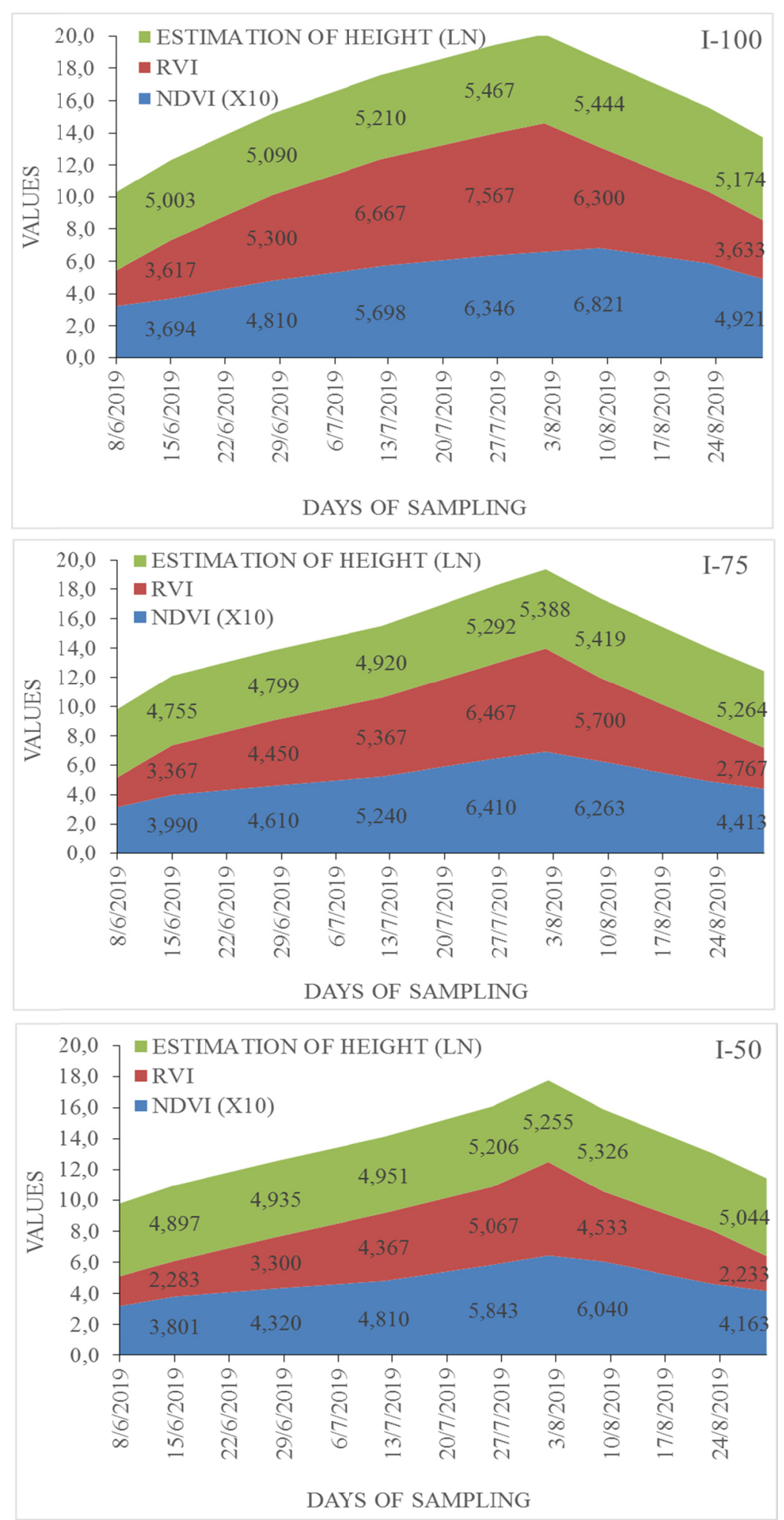

Figure 9. Estimated values of the dependent variable, plant height (Natural Logarithm, LN), in comparison with the independent variables, NDVI (multiplied 10 times) and RVI 


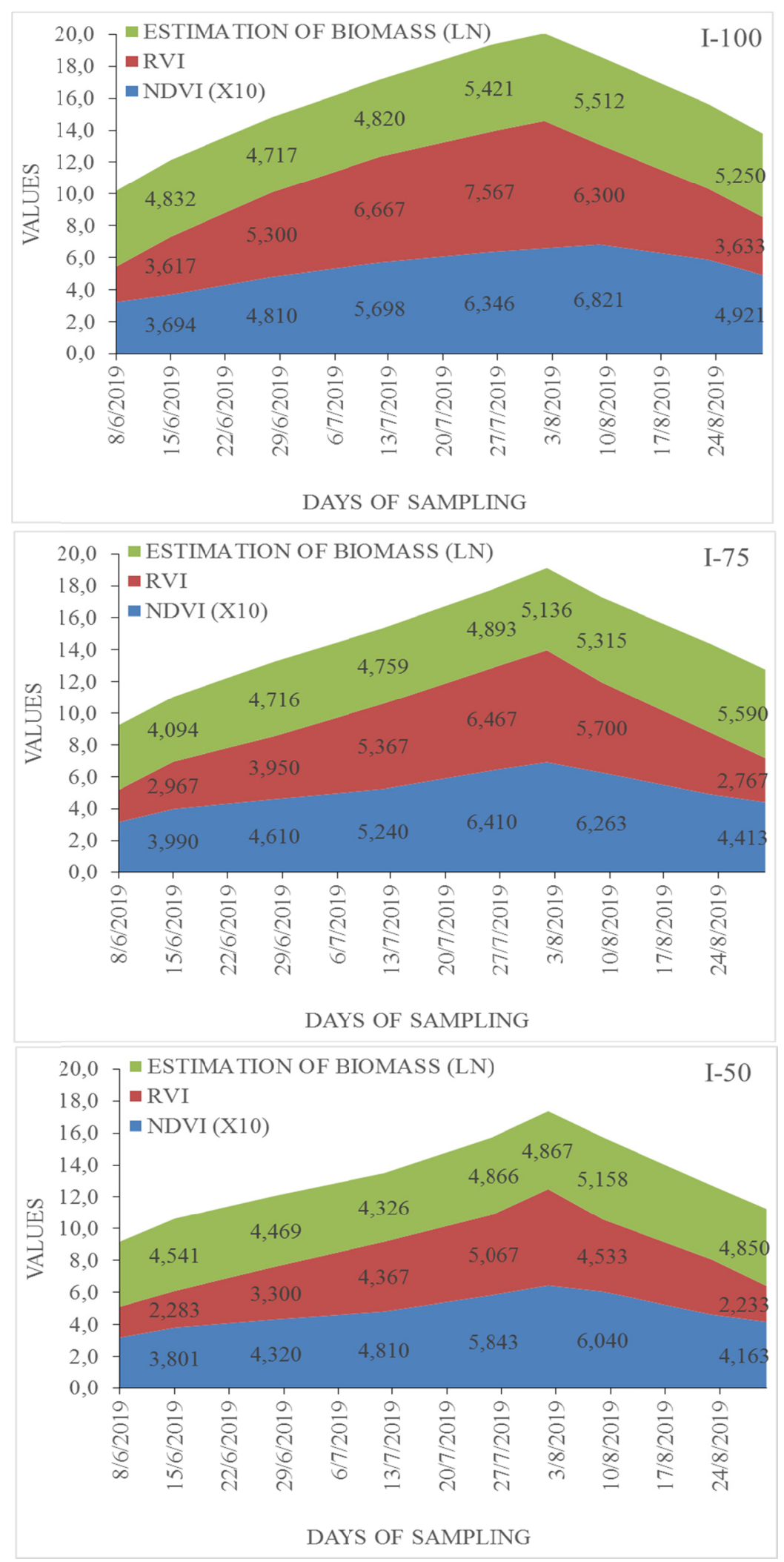

Figure 10. Estimated values of the dependent variable, dry Biomass production (Natural Logarithm, LN), in comparison with the independent variables, NDVI (multiplied 10 times) and RVI 


\section{Discussion}

\subsection{Evaluation of Plant Height, Biomass Production and Water Use Efficiency}

The plants in the I-100 treatment reached a maximum height of 229a cm (mean max height of the 2018 and 2019 periods). The plants in the treatments I-75 and I-50 reached $212 \mathrm{~b}$ and $187 \mathrm{c} \mathrm{cm}$ respectively. It must be noted that the difference in the mean maximum plant height in treatments I-100 and I-75 was only 3\%, which is considered small compared to the difference in irrigation dose (25\% less irrigation dose). The difference between I-75 and I-50 treatments was $12 \%$. This observation is crucial for periods and areas where irrigation water shortages are deficient.

The average maximum dry biomass production for the two years 2018-2019 reached 33900a kg/ha in treatment $\mathrm{I}-100,29400 \mathrm{~b} \mathrm{~kg} / \mathrm{ha}$ in I-75 and $24000 \mathrm{c} \mathrm{kg} / \mathrm{ha}$ the treatment I-50. However, the difference between the I-100 and the I-75 treatment is $13 \%$ while the difference between the I-75 and I-50 is $30 \%$ which means that the dry biomass is more sensitive to deficit irrigation than plant height. The results for both plant height and the dry biomass production are consistent with those in previous researches (Papanikolaou \& Sakellariou-Makrantonaki, 2012; Sakellariou-Makrantonaki et al., 2009; Mygdakos et al., 2009; Karatassiou et al., 2016a, 2016b).

The WUE was higher in the I-50 treatment. This result is significant and predictable as the crop water needs in the I-50 treatment were covered by only 50\% compared to the actual maize water needs (100\% of the I-100), while dry biomass production was quite high. The results are consistent with those in previous researches (Papanikolaou \& Sakellariou, 2012; Karatassiou et al., 2016a, 2016b).

\subsection{Evaluation of the Vegetation Indices Measures}

The NDVI index increases until the first days of August, for each of the three treatments, when its maximum value is recorded. These results are consistent with those of other researches (Ghosh et al., 2003).

According to the data, under the climatic conditions of the area, the RVI index affected by the irrigation dose but not as much as the NDVI one, especially in the treatments where deficit irrigation was applied. These results are consistent with those of other researches (Ghosh et al., 2003).

In contrast to the positive values of the NDVI and RVI indices, the WDRVI values are negative and only the maximum value in the treatments I-100 and I-75 are positive. The results are consistent with those of other researches (Sakamoto et al., 2013).

In contrast with NDVI, RVI, and WDRVI after reaching its pick value, GVI decreases less rapidly than the other three indices. The results are close to those published by Pritsolas and Pearson (2018).

\subsection{Evaluation of the Equations That Estimate the Plant Height and Biomass Production}

According to the results, the plant height can be estimated with equations where Vegetation indices are used as independent variables. It was observed that the WDRVI and the RVI indices were more sensitive in plant height estimation for the fully irrigated plants while the NDVI and the RVI gave equations that best fitted the height evaluation of the plants in the other two treatments. This result can be explained because the NDVI is more sensitive when it is used to describe characteristics of plants that are stressed and with lower canopy (Jin et al., 2015). Those results are consistent with the results about the NDVI of other researches (Payero et al., 2004, Rahetlah et al., 2014).

Biomass production is correlated with plant height (Rahetlah et al., 2014). Thus, the estimation equations were equivalent to those for plant height estimation. The WDRVI and RVI indices were used to estimate the biomass in the I-100 treatment while the NDVI and RVI ones to estimate the biomass in the other two treatments. The biomass production was estimated with acceptable accuracy as shown by other researches too (Llorenç et al., 2011).

From the four different vegetation indices (NDVI, WDRVI, RVI, and GVI) the three were used as independent variables to estimate the plant height and the dry biomass production of corn (dependent variables). Specifically, the RVI index seems to be the most sensitive and is present in all the estimation equations. The NDVI is the second most frequent index in the estimation equations. The WDRVI, a weighted NDVI index, appears only in the estimation equations of the treatment I-100. Five of the six equations predict the dependent variable quite accurately $\left(\mathrm{R}^{2}\right.$ values ranging from $70.5 \%$ to $84.7 \%$ ). In I-50 treatment neither the plant height nor the biomass production could be predicted accurately enough from these four vegetation indices. Finally, the GVI did not appear in any of the equations as it is more sensitive to the leaf chlorophyll content variation and it is not used to predict plant growth characteristics. The validation process of the equations about the height and biomass estimation confirmed the above analyses. In the validation were used the Adjusted Coefficient of Variance, the 
Predicted Residual Error Sum of Squares (PRESS) statistic and the Data Splitting procedure. Further statistical analysis gave a mean value of coefficient of variance of about 26 which is characterized as acceptable for an open field agricultural project (Ehsan, 2018).

As for deficit irrigation, the results showed that both plant height and dry biomass production were lower than those in full irrigation. There were statistically significant differences between the treatments. It must be noted that the average maximum plant height in I-75 treatment was only $3 \%$ lower than the I-100 treatment while in the I-50 treatment it was about $12 \%$ lower than in the I-75 one. The biomass production in the treatment I- 75 was $13 \%$ lower than the I-100 one while in the treatment I-50 was 30\% lower than the I-75. This is a crucial result as in periods or in areas where the irrigation water is limited; the producer can choose between two proposals of deficit irrigation, $75 \%$ or $50 \%$ of the daily evapotranspiration with affordable losses in yield.

\subsection{Advances, Limitations and Future Works}

The use of UAV to take photographs for agricultural purposes is feasible and affordable, economically. It is a new approach to agricultural management and useful equipment in decision-making systems related to the agricultural sector. The key factor is the equipment to get even more affordable. If so, the multispectral cameras which use more than three different bands of the spectrum could be used so that more vegetation indices can be calculated from the same photo and more information about the plant's health can be extracted at the same time. Furthermore, sophisticated software, including software used in photo calibration, could be openly accessed to minimize the total cost of photo analyses. Additionally, the real flight time of the drones must be increased so as to eliminate the need to interrupt the flight to recharge the batteries or to use a large number of them, which is an extra cost.

Further study needs to be conducted to evaluate the effects of other parameters on the climatic conditions of Greece. Such parameters are the resolution of multispectral cameras that use different sensors. Sensors with high resolution give different results in VIs calculations. The height from which the photos are taken may affect the values of the vegetation indices. Photos taken in cloudy conditions may have an effect on the VIs in comparison with photos taken in sunny conditions. The specific VIs values could be different in the same conditions in another area of Greece and consequently, the above equations that estimate the plant height and the biomass production could be the same or vary. Finally, those indices could be used to estimate the same plant characteristics in other crops.

\section{Conclusion}

In this paper, the results of two years (2018-2019) project are presented. The aim was to study if it is feasible to use a drone and a multi-spectral camera to calculate vegetation indices in corn in the Greek climatic conditions and if it is possible to use these vegetation indices to estimate the corn height and its dry biomass production. Three different irrigation doses were applied I-100, I-75, and I-50.

According to the results and the Simple and Multiple regression statistical analysis, both aims were fulfilled. Generally, it is feasible to use a low cost drone and a multispectral camera to take photos and calculate different vegetation indices. Indices such as NDVI, WDRVI and RVI were used as independent variables to estimate dependent variables such as the mean plant height and the dry biomass of corn in medium to high accuracy when different irrigation doses were applied.

\section{References}

Allen, R. G., Pereira, L. S., Howell, T. A., \& Jensen, M. E. (2011). Evapotranspiration information reporting: I. Factors governing measurement accuracy. Agricultural Water Management, 98, 899-920. https:/doi.org/ 10.1016/j.agwat.2010.12.015

Ambrosio, R., Pauletti, V., Barth, G., Pinheiro, P. P., Agostinho da Silva, D., \& Blum, H. (2017). Energy potential of residual maize biomass at different spacings and nitrogen doses. Ciência e Agrotecnologia, 41(6), 626-633. https://doi.org/10.1590/1413-70542017416009017

Bellvert, J., Marsal, J., Mata, M., \& Girona, J. (2012). Identifying irrigation zones across a 7.5-ha 'Pinot noir' vineyard. Irrigation Science, 30, 499-509. https://doi.org/10.1007/s00271-012-0380-y

Ehsan, E. (2018). Re: What are the acceptable values for the percentage deviation (DEV\%) and the coefficient of variance $(C V)$ ? Retrieved from https://www.researchgate.net/post/What_are_the_acceptable_values_for_ the_percentage_deviation_DEV_and_the_coefficient_of_variance_CV/5b96735 $\mathrm{d} 2 \mathrm{a} 9 \mathrm{e} 7 \mathrm{a} 2 \mathrm{ce} 2676 \mathrm{~d} 14 / \mathrm{citatio}$ $\mathrm{n} /$ download 
Foster, J., Kakani, G., \& Mosali, J. (2017). Estimation of bioenergy crop yield and N status by hyperspectral canopy reflectance and partial least square regression. Precision Agriculture, 18(2), 192-209. https://doi.org/ $10.1007 / \mathrm{s} 11119-016-9455-8$

Garside, M. (2020). Brent Crude oil prices from 2014 to 2021. Retrieved May 18, 2020, from https://www.statista.com/statistics/409404/forecast-for-uk-brent-crude-oil-prices

Ghosh, K., Samui, P. R., \& Narayanan, S. P. (2003). Reflectance characteristics of maize and application of vegetation indices for estimation of leaf area index. Quarterly Journal of Meteorology, Hydrology and Geophysics MAUSAM, 54(4), 901-908. https://metnet.imd.gov.in/mausamdocs/154411_F.pdf

Gitelson, A. A. (2014). Wide dynamic range vegetation index for remote quantification of biophysical characteristics of vegetation. Journal of Plant Physiology, 161(2), 165-173. https://doi.org/10.1078/01761617-01176

Howell, T. A., Cuenca, R. H., \& Solomon, K. H. (1990). Crop yield response. In G. J. Hoffman, T. A. Howell, \& K. H. Solomon (Eds.), Management of farm irrigation systems (p. 312). ASAE, St Joseph, MI, USA.

Jiang, Y.-H., Zhang, G., Tang, X.-M., Li, D., Huang, W.-C., \& Pan, H.-B. (2014). Geometric Calibration and Accuracy Assessment of ZiYuan-3 Multispectral Images. IEEE Transactions on Geoscience and Remote Sensing, 52(7), 4161-4172. https://doi.org/10.1109/TGRS.2013.2280134

Jin, X., Yang, G., Xu, X., Yang, H., Feng, H., Li, Z., ... Lan, Y. (2015). Combined Multi-Temporal Optical and Radar Parameters for Estimating LAI and Biomass in Winter Wheat Using HJ and RADARSAR-2 Data. Remote Sensing Journal, 7, 13251-13272. https://doi.org/10.3390/rs71013251

Karatassiou, E., Papanikolaou, C., \& Sakellariou-Makrantonaki, M. (2016a). The effect of different irrigation methods in biodiesel production from sunflower. Journal of Irrigation and Drainage Systems Engineering, 5(2). https://doi.org/10.4172/2168-9768.1000166

Karatassiou, E., Papanikolaou, C., \& Sakellariou-Makrantonaki, M. (2016b). Biodiesel production from sunflower in Greece. MedCrave Open Journal of Civil Engineering, 2(3), 00036. https://doi.org/10.15406/ mojce.2017.02.00036

Latifia, H., Fassnacht, E. F., Hartig, F., Bergere, C., Hernandez, J., Corvalan, P., \& Koch, B. (2015). Stratified aboveground forest biomass estimation by remote sensing data. International Journal of Applied Earth Observation and Geoinformation, 38, 229-241. https://doi.org/10.1016/j.jag.2015.01.016

Llorenç, C.-B., Molero, G., Stellacci, M. A., Bort, J., Nogués, S., \& Araus, J.-L. (2011). NDVI as a Potential Tool for Predicting Biomass, Plant Nitrogen Content and Growth in Wheat Genotypes Subjected to Different Water and Nitrogen Conditions. Cereal Research Communications Journal, 39, 147-159. https://doi.org/10.1556/CRC.39.2011.1.15

Montgomery, C., \& Runger, C. (2003). Applied Statistics and Probability for Engineers (3rd ed). New York, USA: John Willey and Sons.

Mulla, J. D. (2013). Twenty five years of remote sensing in precision agriculture: Key advances and remaining knowledge gaps. Biosystems Engineering, 114(4), 358-371. https://doi.org/10.1016/j.biosystemseng.2012. 08.009

Mygdakos, E., Papanikolaou, C., \& Sakellariou-Makrantonaki, M. (2009). Sorghum economics under different irrigation methods and water doses. New Medit Journal, 8(4), 47-54. Retrieved May 18, 2020, from https://newmedit.iamb.it/share/img_new_medit_articoli/274_47mygdakos.pdf

Papanikolaou, C., \& Sakellariou-Makrantonaki, M. (2012). The effect of an intelligent surface drip irrigation method on sorghum biomass, energy and water saving. Irrigation Science, 31(4), 807-814. https://doi.org/ 10.1007/s00271-012-0344-2

Papoutsidakis, M., Drosos, C., Symeonaki, E., \& Tseles, D. (2018). The biomass as an energy source and its application benefits. International Journal of Engineering Applied Sciences and Technology, 2(10), 1-5. Retrieved from http://www.ijeast.com

Payero, O. J., Neale, U. M. C., \& Wright, L. J. (2004). Comparison of eleven vegetation indices for estimating plant height of alfalfa and grass. Applied Engineering in Agriculture, 20(3), 385-393. https://doi.org/ $10.13031 / 2013.16057$

Potgieter, B., George-Jaeggli, B., Chapman, C., Laws, K., Suarez Cadavid, A., Wixted, J., ... Hammer, L. (2017). Multi-spectral imaging from an unmanned aerial vehicle enables the assessment of seasonal leaf area 
dynamics of sorghum breeding lines. Frontiers in Plant Science, 8, 1-11. https://doi.org/10.3389/fpls.2017. 01532

Pritsolas, J., \& Pearson, R. (2018). An assessment of vegetation indices'relationship to crop yield. Iowa Soybean Association Farmer Research Conference. Retrieved on May 18, 2020 from https:/www.iasoybeans. com/upl/downloads/publications/2018-farmer-research-conference-vegetation-indices-relationship-to-cropyield.pdf

Radhadevi, P. V., Solanki, S. S., Akilan, A., Jyothi, V. M., \& Nagasubramanian, V. (2016). Performance Assessment and Geometric Calibration of Resourcesat-2. The International Archives of the Photogrammetry. Remote Sensing and Spatial Information Sciences, XLI-B1, 237-244. https://doi.org/10.5194/isprs-archivesXLI-B1-237-2016

Rahetlah, B. V., Salgado, P., Andrianarisoa, B., Tillard, E., Razafindrazaka, H., Le Mézo, L., \& Ramalanjaona, L. V. (2014). Relationship between normalized difference vegetation index (NDVI) and forage biomass yield in the Vakinankaratra region, Madagascar. Livestock Research for Rural Development Journal, 26(5), Article 95. Retrieved May 18, 2020, from http://www.lrrd.org/lrrd26/5/rahe26095.html

Sakamoto, T., Gitelson, A., \& Arkebauer, T. (2013). MODIS-based corn grain yield estimation model incorporating crop phenology information. Remote Sensing of Environment, 131, 215-231. https://doi.org/ 10.1016/j.rse.2012.12.017

Sakellariou-Makrantonaki, M., Papanikolaou, C., \& Mygdakos, E. (2009). Fiber sorghum biomass yield, water use efficiency and economic results under different levels of water, using subsurface and surface irrigation systems. Fresenius Environmental Bulletin, 18(9), 1624-1632. Retrieved May 18, 2020, from https:/www.prt-parlar.de/download_feb_2009/FEB_09_2009.pdf

Shawn, H. (2017). Discover NDVI and its valuable uses in agriculture. Retrieved from https://botlink.com/blog/discover-ndvi-and-its-valuable-uses-in-agriculture

Sruthi, S., \& Aslam, M. A. M. (2015). Agricultural Drought Analysis Using the NDVI and Land Surface Temperature Data: A Case Study of Raichur District. Aquatic Procedia, 4, 1258-1264. https://doi.org/ 10.1016/j.aqpro.2015.02.164

Sun, Q., Zhang, X., \& Jiang, M. (2011). Eco-environment variable estimation from remote sensed data and eco-environment assessment: models and system. Acta Botanica Sinica, 4, 1073-1080.

SunEarthTools. (2020). Tools for consumers and designers of solar. Retrieved May 18, 2020, from https://www.sunearthtools.com/dp/tools/pos_sun.php?lang=en

Toureiro, C., Serralheiro, R., Shahidian, S., \& Sousa, A. (2017). Irrigation management with remote sensing: Evaluating irrigation requirement for maize under Mediterranean climate condition. Agricultural Water Management, 184, 211-220. https://doi.org/10.1016/j.agwat.2016.02.010

Tursi, A. (2019). A review on biomass: importance, chemistry, classification, and conversion. Biofuel Research Journal, 22, 962-979. https://doi.org/10.18331/BRJ2019.6.2.3

Xue, J., \& Su, B. (2017). Significant remote sensing vegetation indices: A review of developments and applications. Hindawi Journal of Sensors, 2017, 1-17. https://doi.org/10.1155/2017/1353691

Xue, L., Cao, W., Luo, W., Dai, T., \& Zhu, Y. (2004). Monitoring leaf nitrogen status in rice with canopy spectral reflectance. Agronomy Journal, 96(1), 135-142. https://doi.org/10.2134/agronj2004.1350

\section{Copyrights}

Copyright for this article is retained by the author(s), with first publication rights granted to the journal.

This is an open-access article distributed under the terms and conditions of the Creative Commons Attribution license (http://creativecommons.org/licenses/by/4.0/). 